\title{
Violencia, mujer y televisión
}

\author{
María Magdalena García Toledo \\ Universidad Nacional Mayor de San Marcos \\ magda2044@yahoo.com
}

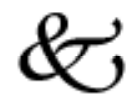

\begin{abstract}
Resumen
El presente estudio es una investigación acerca de la violencia ejercida contra la mujer, específicamente en la televisión de señal abierta de Lima Metropolitana. Es bien conocido el fenómeno de la violencia ejercida por la sociedad que se traduce en una serie de consecuencias negativas de orden político, social, educativo, económico y legal contra la mujer y que se constituye en un problema mundial más allá de las clases sociales y del tipo de sociedad. Por otra parte se analiza el papel que le compete a los medios de comunicación -en este caso la televisión- de refuerzo de las conductas sociales y creadores de ideologías y formas de vida que no se condicen con las necesidades de sociedades como las nuestras en proceso de desarrollo humano e integral.
\end{abstract}

Palabras claves: Violencia, mujer, medios de comunicación social.

\begin{abstract}
The present study is an investigation into violence against women, specifically in the television airwaves of Lima. It is well known phenomenon of violence by society resulting in a series of negative consequences of political, social, educational, economic and legal against women and establishing a global problem beyond social classes and the type of society. This study also examines the paper that it falls to the media-in this case television, reinforcing social behaviors and creators of ideologies and lifestyles that are consistent with the needs of societies like ours in the process integral human development
\end{abstract}

Keywords: Violence, Women, Social media. 


\section{Introducción}

En nuestro país, cada año se profundiza la gravedad del problema de violencia contra la mujer traducido en cifras que hablan de asesinatos, agresiones, violaciones y toda serie de injurias contra la mujer. Son los medios de comunicación los que informan permanentemente de estos hechos revistiéndolos en muchos casos de una suerte de sensacionalismo y otros defectos que no permite la toma de conciencia y la real percepción de la mujer como sujeto social valioso.

La metodología consistió en la selección y grabación de programas televisivos que tienen gran audiencia en nuestro medio. Se aplicó el análisis de contenido y las variables principales fueron la violencia física, la violencia psicológica, la violencia sexual y la violencia económica.

Los objetivos de esta investigación son: describir y analizar la imagen que sobre la mujer presenta la televisión de señal abierta en Lima Metropolitana; analizar la forma como son presentadas las noticias sobre la violencia contra la mujer: y analizar la importancia relativa que se da a este género de noticias en la programación televisiva.

La investigación consta de las siguientes partes:

- Un marco teórico donde se desarrollan conceptos relacionados con la violencia, con el género femenino y con el tratamiento de la información que realizan los medios de comunicación social, especialmente la televisión.

- Un diagnóstico de la violencia conyugal en el Perú, violencia que se ha revelado como la más generalizada, la más grave y que va en aumento y la que privilegian los medios de comunicación social.

- Un análisis de cómo los medios de comunicación abordan la información de la violencia contra la mujer. Este análisis se ha llevado a cabo mediante la observación de los actos de violencia contra la mujer que la televisión emite dentro de la programación de señal abierta, especialmente dentro de los géneros más populares, como son los programas cómicos, los de entretenimiento, los noticieros y las series televisivas.

- Discusión y conclusiones.

- Anexos.

- Referencias bibliográficas.

\section{Diseño, método e hipótesis}

Esta investigación es de nivel descriptivo y transversal. El método principal es la observación de una muestra de programas televisivos de mayor audiencia, empleando el Análisis de Contenido con las categorías siguientes: violencia física, violencia psicológica, violencia, sexual y violencia económica. 
Las hipótesis que guiaron la investigación son:

1. Los medios de comunicación social presentan en general una imagen negativa de la mujer en nuestra sociedad.

2. La televisión de señal abierta de Lima Metropolitana privilegia la información de violencia contra la mujer desde un punto de vista sensacionalista que no contribuye a la solución efectiva del problema.

\section{Marco conceptual y referencial}

\section{Marco Teórico sobre la Violencia}

Antes se pensaba que la violencia se debía principalmente a un transtorno mental del agresor, el uso inmoderado del alcohol y las drogas. Otro factor que se señalaba era la comunicación conflictiva entre los cónyuges, así como la reproducción de la violencia que hacían las personas que habían pertenecido a familias violentas. Estos enfoques ya han sido superados por el avance de las ciencias sociales y psicológicas en pro de explicaciones que tomen en cuenta diferentes factores socioculturales, coyunturales y personales.

El enfoque sistémico concibe la violencia como un producto derivado de las relaciones entre múltiples variables, donde la responsabilidad de la violencia es mutua, donde no hay agresores ni agredidos, sino que los dos miembros de la pareja tienen que ver con la forma en que se comunican. Este enfoque ha sido cuestionado porque no explica el carácter unidireccional de la violencia del hombre contra la mujer que las estadísticas se encargan de ilustrar profusamente. Esto nos lleva a los grupos vulnerables -mujeres, niños, ancianos, discapacitados y personas diferentes- donde la edad, el sexo, el nivel educativo, la desprotección legal, el desconocimiento y atropello de los derechos fundamentales, representaciones sociales desvalorizantes, parecen explicar la inequidad social.

El enfoque ecológico plantea dimensiones macro, meso, micro e individual que afectan a la familia. En el nivel macro están el Estado y los gobiernos regionales y locales, así como los valores y mitos que determinan los roles de género de una sociedad. En ciertas culturas, por ejemplo, se acepta el rol pasivo y sumiso de la mujer y el carácter dominante del hombre. .En el nivel meso se consideran la escuela, la iglesia, los medios de comunicación, los centros laborales, la pobreza, la falta de trabajo, las migraciones, la falta de vivienda, el aislamiento de la mujer y la asociación del agresor con delincuentes donde es apreciada su "hombría". El nivel microsistema es el nivel donde se da la relación interpersonal e íntima, allí se encuentra la familia como el grupo social más importante. Según los estudiosos es aquí donde es más factible encontrar la violencia dada por el carácter patriarcal de la familia, donde el manejo 
del poder no es equilibrado. Pero es la familia machista la más productora de violencia. El nivel individual está dado por las dimensiones cognitivas de cada cual, las conductas, el aspecto intrapsíquico como las emociones, y conflictos y la dimensión interaccional que tiene que ver con las relaciones establecidas y sus modos de comunicación.

Aquí se estudia el enfoque de género como el conjunto de significados, prácticas, símbolos, representaciones, instituciones y normas que la sociedad ha elaborado para el hombre y la mujer. Lo que se observa es que hay una desigual distribución del poder y de la valoración de lo femenino y lo masculino. Esto determina la violencia familiar como un fenómeno social que se da en determinadas culturas.

\section{La violencia contra la mujer en el Perú}

En el estudio del Instituto Nacional de Estadística e Informática (2006) sobre violencia conyugal que resume muchas investigaciones sobre la violencia contra la mujer, se ofrecen los siguientes datos.

En primer lugar, se parte de ciertas consideraciones teóricas que pueden resumirse así:

1. En las sociedades latinoamericanas predomina la familia machista en contraposición de la familia patriarcal. Mientras ésta última asume una función protectora de la familia, la primera es destructiva, tendiente al dominio de la mujer y sin responsabilidad para con los hijos. Este patrón se da desde la conquista española con la unión sexual de conquistadores y mujeres nativas.

2. Ciertos cambios en los procesos sociales, políticos, demográficos y económicos, explican la aparición de la familia democrática dándose un mayor control de la reproducción, nuevas expectativas educativas para la mujer, la ampliación del concepto de derechos humanos y las nuevas oportunidades en el mundo laboral. Todo esto ha hecho que se cuestione muy fuertemente el tipo de familia patriarcal.

3. Estos cambios sin embargo no son procesados fácilmente. La familia patriarcal está asentada en un sistema fuerte y muy antiguo y no es fácil desmontarla. Esto da lugar a conflictos familiares y a la violencia como expresión de grandes tensiones y resistencia a los cambios.

4. Los mecanismos de reproducción social de las familias, en este caso de la familia patriarcal, tienen lugar desde la socialización temprana de niños y niñas, en la cual se aprenden los códigos de comportamiento referidos a una manera de ser y hacer masculino así como de ser y hacer femenino.

5. Las familias aprenden, sobre todo los niños, en los procesos de socialización, por el mundo del trabajo y en general en las relaciones sociales y 
políticas, que hay un género dominante y otro género dominado que corresponde a la madre, uno que manda y el otro que obedece, y que el que manda está justificado para usar la violencia.

6. La violencia familiar tiene características peculiares según la zona del país donde se dé, según también se hable de familias urbana o campesinas y amazónicas.

7. La violencia contra la mujer es socialmente admitida cuando ella intenta traspasar los límites permitidos por una sociedad patriarcal, aunque bajo determinados controles sociales.

\section{Diagnóstico}

La mayoría de mujeres agredidas pertenecen a familias numerosas, cuyas uniones tienen una antiguiedad mayor a 15 años, son convivientes y en muchos casos se trata de viudas, divorciadas y separadas, hay mayor violencia cuando se unen siendo menores de edad, así como haber tenido la primera relación sexual a los 15 años de edad o menos. El nivel educativo no sobrepasa el nivel primario incompleto.

Geográficamente, los fenómenos de violencia se encuentran en la sierra, sobre todo en la selva alta, sin distinguirse la zona urbana de la rural pero sí en los lugares donde hubo violencia política. En este sentido, Cusco, Arequipa, Tacna, Apurímac son los departamentos con los niveles más altos y frecuentes de violencia contra la mujer. Se observa que son las mujeres que hablan quechua las más agredidas en comparación a las que hablan español.

Las parejas agresoras tienen 50 o más años de edad, la mayoría con sólo nivel educativo primario, son trabajadores manuales no calificados Asimismo son varones que consumen alcohol con frecuencia. Se observó que a mayor control a la mujer (no permitirle que estudie, que tenga amigas y visite a los parientes), mayor violencia. Cuando la mujer decide sola, lo cual es recibido por el varón como una provocación, recibe igualmente mayor violencia.

Existe una asociación positiva entre violencia y familia patriarcal, mayor control a la mujer a la que se le relega a las tareas domésticas. El INEI encontró que hay mayor violencia cuando la mujer trabaja y se dedica al cuidado de la salud y la cocina. También se encontró que la mujer menor de edad es considerada por el marido como una niña en cuyo sometimiento no es necesario emplear la violencia. Asimismo, a mayor autoritarismo del marido mayor violencia, por ejemplo, cuando el marido decide solo el gasto del dinero que ella gana, esto revela un rasgo más del machismo que se expresa en explotación de la mujer.

Se observó también que hay mayor violencia cuando la mujer hace uso de métodos anticonceptivos sobre todo de los modernos, lo que evidencia la au- 
tonomía femenina que no es tolerada por el marido. También cuando la mujer se niega a tener relaciones sexuales es más agredida

Es de observar que las mujeres más agredidas físicamente son más proclives al castigo físico a los hijos como método educativo. Y esto se refuerza cuando la mujer ha sido testigo de violencia en su infancia por parte de su padre contra la madre, así como cuando ella misma ha sido víctima de castigo físico con golpes, quemaduras, palmadas y sumergimiento en el agua, o retiro del afecto, ignorarla o "rezondrarla".

La violencia contra la mujer no está asociada al nivel socioeconómico, sin embargo se encontró que el nivel de violencia se duplica cuando la mujer aporta económicamente al hogar y cuando su trabajo es doméstico, manual y no calificado, siendo menor cuando ella es profesional o tiene un trabajo especializado.

El INEI comprobó la hipótesis en el sentido que la violencia familiar y sexual sufrida por la mujer afecta severamente las condiciones generales de vida de sus hijos, una de cuyas consecuencias es el mayor porcentaje de fallecimiento de los hijos y pérdida en los embarazos, así como mayor incidencia de diarrea en los niños. Se observó también que en los hogares con mayor violencia el número de niños registrados en las Municipalidades es menor.

Las consecuencias para la mujer también son severas: hay un descuido en su salud general, su salud reproductiva y sexual y su participación en el trabajo. En investigaciones del 2004 se encontró una fuerte asociación entre la violencia reciente y el haber sufrido moretones y dolores, rotura de huesos y la necesidad de ir al doctor. Entre estas mujeres, la posibilidad de otro embarazo es un gran problema. Existe asociación de violencia física con síntomas de enfermedad durante el embarazo, sangrado excesivo, desmayos, fiebre alta, infección mamaria, infección urinaria, descarga genital y pérdida involuntaria de orina. También existe la posibilidad de contraer SIDA y se ha encontrado que el doble de ellas han recibido ofertas de dinero por sexo.

En las familias que sufren violencia se observó que los niños viven fuera del hogar, hay desintegración familiar o disolución del vínculo conyugal

En general, la mujer no pide ayuda frente a la violencia, por minimización del problema y creer que los daños no fueron fuertes, la baja autoestima, creer que pueda resolver el problema sola, que no volverá a ocurrir, que ella tiene parte de culpa, la verguienza de comunicarlo o pensar que es parte de la vida, en otras palabra se ve el problema como algo natural y esto puede deberse a su formación desde niña. Se ha observado sin embargo, que cuando pide ayuda es porque la mujer ha estado más expuesta a los medios de comunicación, aun cuando se reconoce que éstos no ofrecen una educación y orientación eficaz que haga que la mujer pueda mejorar su situación o pedir una ayuda eficaz. 


\section{El tratamiento que dan los medios a la violencia}

Ya es un lugar común considerar a la televisión como el medio paradigmático por excelencia, omnipresente en la vida contemporánea y agente socializador de primer orden para las gentes por su innegable influencia en los modos de percibir, pensar y actuar. Casi desde los inicios de la televisión, las investigaciones sobre violencia han estado presentes en el escenario mundial, sobre todo en el mundo de los niños, los adolescentes y los grupos más vulnerables, entre los cuales se incluye a la mujer. En ese sentido, uno de los temas de investigación más importante es cómo se legitima la violencia en los medios de comunicación, legitimación que hace creíble lo que se presenta allí y por lo tanto lo que influirá de un modo u otro a la sociedad. Legitimar significa presentar conductas como normales y por lo tanto aceptables.

Hay muchos mecanismos para legitimar la violencia. Entre ellos, están los "héroes", personajes "legales" como la policía, o los padres y educadores, a los cuales se les permite este tipo de actos, sobre todo si actúan buscando el bien. Esto se refuerza más si las víctimas son presentadas como delincuentes, locos, antipáticos y "malos". Asimismo, ocultar las consecuencias negativas o positivas es otro recurso de legitimación de la violencia.

Existen procesos de legitimación también en la sociedad, sin embargo es en la televisión donde estos mecanismos son más aceptados, sobre todo en los géneros ficcionales.

Por otra parte, es necesario reconocer que los medios tienen todo el derecho de presentar la violencia pero están obligados a explicarla, contextualizarla para que el espectador saque conclusiones informadas y veraces.

No puede olvidarse también lo que muchos teóricos de la comunicación han hablado sobre el efecto desinhibidor de la violencia. Se plantea que ante tanta muestras de violencia en los medios, casi saturación, las personas pueden ir acostumbrándose a ella e ir perdiendo sensibilidad. Es muy común observar cómo los conflictos se solucionan a la primera con la agresión física y no como hablan los códigos de derechos humanos y de ética, que sostienen que debe primar los procesos de conciliación, respeto y tolerancia, en otras palabras, que debe primar la paz y la solución pacífica de los conflictos. "Pero el verdadero debate social sobre la violencia en televisión tendría que centrarse en qué formas de legitimación o deslegitimación nos parecen adecuadas a nuestro ordenamiento jurídico y si ciertas formas de legitimación o deslegitimación de la violencia no estarían contribuyendo a extender mensajes discordantes o contradictorios con nuestras reglas de convivencia" (FERNÁNDEZ: 2007).

Frente a este panorama, hoy se exige a los medios que contribuyan de otra manera para eliminar la violencia, se habla inclusive de una labor educativa de los medios que ayude a superar una diversidad de problemas en el tratamiento 
de la información que distorsiona la imagen de la mujer y refuerza las malas prácticas, que pese a los esfuerzos de profesionales conscientes que quieren un cambio, se siguen dando a nivel mundial.

Hay que entender la resistencia numantina de los medios a modificar sus contenidos y el tratamiento que hacen de los relatos -tanto de ficción como de no ficción- sobre hombres y mujeres en torno a tres ejes principales. Por una parte, los intereses económicos de los grandes grupos mediáticos que aseguran resultados elaborando relatos que apoyan y fortalecen los valores sociales dominantes sobre los cuales se asienta su negocio; en segundo lugar, la falta de sensibilidad y de conciencia social de la profesión periodística, asentada en la también falta de conocimiento y de formación sobre el tema, y por último, el tercer eje se situaría en los procesos y rutinas de producción que obliga a la profesión a reproducir a menudo las noticias de agencia, sin el tiempo necesario para contextualizar, documentarse, contrastar fuentes; en una palabra, para elaborar información de calidad (López: 2002).

En este sentido, se plantean las siguientes tareas para un nuevo tratamiento informativo del tema que nos ocupa:

1. Revalorar la imagen de la mujer, superando su presencia medial como objeto sexual, doméstico, pasivo y de víctima, en pró de una imagen que la muestre en toda su real valía. Así, por ejemplo, mostrarla en otros roles como profesionales, artistas, políticas, escritoras, empresarias, agrónomas y en las múltiples tareas que ella realiza en la vida real.

2. Superar el tratamiento noticioso que obliga a un trabajo superficial, urgente, donde los datos no se confirman como debe ser, y en general no se investiga, por lo tanto se presentan las noticias de una manera que no permite informarse plenamente, contextualizar el problema, encontrar las causas y las consecuencias, analizar en una palabra el problema y pensar en su solución.

3. En relación con lo anterior, es necesaria la especialización de ciertos periodistas para informar de manera diferente a como ahora se hace y no que se dé un valor sólo "policial" a la información sobre violencia. Esto conlleva a un uso creativo de los diversos géneros informativos al servicio de la tarea informativa, una de las cuales es por ejemplo el debate del problema, momento en el que se analiza y profundiza un hecho, dándole al público más y mejores elementos que le permitan una perspectiva completa y veraz de la información. Lo mismo puede deducirse de la necesidad de buscar datos fidedignos y no la compra de información por ejemplo en las comisarías, el reparto de estos datos entre periodistas de diferentes medios y su uso a veces político como "cortina de humo", práctica de la que todo el mundo tiene conocimiento. Todo esto permitirá superar la rutinización de la noticia que desfavorece la nueva manera de informar que se propugna. 
4. En relación con lo anterior también es necesario superar la mala costumbre de los lugares comunes, el uso de términos clichés que resumen distorsionando el hecho noticioso, un lenguaje estandar que simplifica el problema, reduciéndolo peligrosamente. Un ejemplo de esto lo vemos en el uso de titulares hasta parecidos en diferentes medios para impresionar fácilmente al público frivolizando la noticia buscando sólo el rating o venta de medios.

5. Uno de los problemas mayores del tratamiento de la violencia medial es la espectacularización del hecho informativo. Esta característica típica de la televisión que convierte en espectáculo todo lo que presenta, lamentablemente a veces es llevada a la exageración, lo que conlleva a un tratamiento con resultados diferentes a los que debe tener.

La escasa educación audiovisual del público con el espectáculo como referencia, y la búsqueda de audiencia por encima de consideraciones éticas, nos sitúa en ocasiones ante perversiones informativas que en nada contribuyen a una mejor comprensión del problema. Llamar la atención sobre los aspectos más dramáticos para buscar espectacularidad puede aumentar la conmiseración por las víctimas pero hacer, al tiempo, que se pierda la perspectiva global. En el caso de la televisión existe un mensaje verbal, y un mensaje no verbal. Determinado tipo de escenografías, vestuario o puestas en escena no ayudan a dar al tema de la violencia doméstica contra las mujeres la importancia y gravedad que se merece. Tampoco contribuye a ello determinadas denuncias en programas late night a cargo de conocidos personajes del mundo del corazón, en un marco de frivolidad y espectáculo (Rodigou: 2007).

6. El sensacionalismo sigue siendo un problema mundial y en nuestro país sucesivas investigaciones lo confirman, sobre todo con el problema de la prensa amarilla o prensa "chicha" que también se da en la televisión. Son conocidos los noticieros televisivos de la televisión de señal abierta que privilegian este estilo y que tienen una gran audiencia sobre todo en los sectores populares. "Soñó que le era infiel y la mató" es un titular que se repite de cuando en cuando ante la aparente falta de noticias. Fácil es deducir los resultados de este tipo de informaciones.

7. Debe cuidarse también lo que dicen los representantes policiales y legales frene a los hechos de violencia que venimos tratando. Es conocido el hecho de que se tuvo que instituir comisarías de mujeres que recibieran y procesaran correctamente las denuncias de mujeres que habían sufrido violencia ya que los varones desestimaban y hasta se negaban a atenderlas diciéndoles que seguramente ellas tenían la culpa de lo que había pasado y en general exculpaban a los varones. Este mismo hecho se da en la televisión donde a veces, jueces, policías, abogados, comentan cosas que denigran a la mujer, 
ofreciendo una perspectiva "machista" y desvalorizadora de la mujer. "No es un crimen porque no la mató", "Fue en un arranque de celos" "Es un crimen pasional" (presentando casi como víctima al hombre y minimizando su crimen), etc.

8. En las recomendaciones de nuevo tratamiento informativo sobre violencia, se hace hincapié que es necesario no sólo presentar un hecho de este tipo, sino también realizar un seguimiento detallado, por ejemplo, sentencias ejemplares, seguimiento judicial de un agresor, evitar que regrese al domicilio conyugal, para que la opinión pública observe que no hay impunidad en estos delitos.

Es importante por lo tanto percibir la violencia contra la mujer no como un problema delincuencial, aislado y fortuito sino como un problema social, donde impera el dominio de un género contra el otro, donde se da una distribución inequitativa del poder, donde todavía las oportunidades, la promoción y la imagen de la mujer no logra un real status que la valorice en toda su integridad.

La información por lo tanto debe cambiar, privilegiando por encima de los intereses económicos de las empresas de comunicación, un real interés por un grupo humano tan importante como son las mujeres.

En el trabajo "Mujer, violencia y medios de comunicación" del Instituto Oficial de Radio y Televisión española: (RTVE: 2002) se propone un Manual de Urgencia que plantea los siguientes principios que vamos a resumir:

1. Evitar los modelos de mujer que lesionen su dignidad. Ya hemos explicado este punto, hay que mostrar a la mujeres en otros roles que superen las imágenes de "misses", modelos, vedettes, amas de casa tradicionales y otros, que no la muestren como lo que es.

2. Los malos tratos contra las mujeres atentan contra los derechos humanos. Los malos tratos son un delito, un problema social y nos concierne a todos y a todas. Los malos tratos no son un asunto privado, ni doméstico, ni un suceso fortuito o desgraciado.

3. No confundir el morbo con el interés social. El estilo espectacular de la televisión no es el más adecuado para tratar el problema.

4. La violencia contra las mujeres no es un suceso, ni una noticia convencional... Merece análisis, reflexión, contextualización y no inclusión en la crónica roja o negra típica de nuestro periodismo.

5. No todas las fuentes informativas son fiables. Hay testimonios y comentarios que aportan y otros que confunden, hay que seleccionar con criterio lo verdaderamente útil y que contribuya a una buena comprensión del problema.

6. Dar información útil, asesorarse previamente. 
7. Identificar la figura del agresor, respetar la dignidad de la víctima. El agresor debe ser identificado claramente, si no con su identidad, dadas las cautelas judiciales, sí en cuanto a su comportamiento. Se trata de ayudar a otras mujeres a identificar la figura del maltratador. En cuanto a la víctima, no se puede mostrarla sin su permiso, ni en momentos de tensión emocional. Respetar su dolor y esperar a que recupere la autoestima y el equilibrio. Será más útil, y menos morboso.

8. La imagen no lo es todo, no caer en el amarillismo.

9. Las cifras pueden referirse a distintas realidades: informarse y explicar.

10. Los estereotipos y los tópicos frivolizan y banalizan.

\section{Análisis de una muestra de la TV abierta de Lima Metropolitana}

Se ha analizado una muestra de la programación televisiva de señal abierta de Lima Metropolitana para captar los hechos de violencia contra la mujer tanto en programas informativos, como en los de ficción y programas cómicos. Estos programas son los que cuentan con la mayor audiencia en nuestro medio. Presentamos algunos casos típicos:

1. El caso de Elizabeth Alanya, quemada con agua hervida, y que los canales de noticias han transmitido con detalles, ya que ella se convirtió en un símbolo de la lucha de la mujer contra esta violencia. En su caso no sólo hubo agresión física, sino también psicológica a través de insultos, amenazas, prohibiciones, coacciones y omisión ante sus necesidades por parte del marido. También sufrió violencia económica ya que el marido le robó y destruyó algunos de sus bienes. El apoyo que recibió de algunas organizaciones de mujeres, legales y otras, permitió que su caso fuera analizado mejor y se superara la simple información como un hecho delincuencial más.

Lo que llamó la atención en uno de los reportajes fue el comentario de la Fiscal del caso que expresó que echar agua hervida no era delito porque no la mató. Como vemos, el maltrato no solo fue del marido sino de los representantes legales que se supone deben aplicar la ley correctamente.

2. La humillación de Charo por parte de la suegra y el hijo mayor. Programa "Al fondo hay sitio" en América Televisión. En este programa, en concreto, la protagonista sufre pasivamente los insultos, humillación, gritos y desprecio de su hijo y suegra. Ella representa una mujer ama de casa con un nivel educativo medio y se caracteriza por una imagen conservadora y pasiva de la mujer que parece tener mucha aceptación en los sectores populares. El problema de la escena no es el aparente conflicto suscitado sino la pasividad mostrada que si bien puede ser característica del personaje, precisamente por abundar en nuestra televisión este tipo de mujer, no propicia la valoración de sus derechos y su dignidad, presentándose más bien como un ideal de mujer sumisa, pasiva y "buena”. 
3. La paisana Jacinta es denigrada por su empleadora por ser provinciana, llamándola sucia. Canal de Frecuencia Latina. Ya es conocida la protesta de algunas organizaciones femeninas y otras que han criticado fuertemente este programa, por presentar la imagen de la mujer indígena de una manera grosera, ridícula y que no refleja de ninguna manera a la mujer del interior del país. La comicidad no puede ser pretexto para denigrar a la mujer. En este programa en concreto, la paisana es agredida como sucia por su empleadora que le niega su sueldo, ejerciendo con ello violencia económica y le prohíbe sentarse porque le va a ensuciar sus muebles. Lo cómico del asunto no oculta el problema generalizado de las empleadas del hogar que sufren una serie de agresiones y violencias en sus derechos fundamentales.

4. Dorita Orbegozo es retratada como tramposa en el programa de Magaly TV, Canal ATV. Allí se le llama infiel, tramposa y se desliza que es una mujerzuela, al sorprendérsele con otro galán que no es su pareja habitual. Este tipo de hechos es típico en el programa de Magaly que alimenta el morbo de la gente con sus "denuncias" erigiéndose ella en modelo de mujer honesta. Sus víctimas directas son personas de la farándula, el fútbol y otros famosos. En este caso concreto, se observó que al día siguiente de la emisión del programa, la prensa escrita reprodujo el hecho llamándola de nuevo tramposa y al marido cachudo., con lo que vemos el refuerzo que se dan los medios entre sí frente a hechos escandalosos.

Otros dos incidentes se produjeron frente a este caso. A Dorita, actriz cómica, la filmaron desnuda, sin su consentimiento, en los ambientes del Ejército, donde había ido a cumplir un trabajo. Ella denunció el hecho pero el plato ya estaba servido en la prensa y la televisión. Este último medio se encargó de difundir profusamente el video correspondiente, sin que la actriz pudiera hacer nada, a pesar de su protesta de que se trataba de un caso judicial. El objetivo no era sólo informar sino crear sensacionalismo e indirectamente la imagen de la actriz fue mellada.

El segundo incidente se dio en una presentación de la actriz que se quejó que estaba sola y necesitaba cariño. Uno de los espectadores, un varón, inmediatamente se levantó, se acercó a ella y le besó el trasero. También este hecho fue ampliamente difundido por los medios.

Como vemos, las actrices, vedettes y mujeres pertenecientes al espectáculo son blanco de este género de noticias, y no suscitan en el público compasión o siquiera simpatía, sino que se dice que se lo buscó, que lleva una mala vida y que eso le pasa por ser lo que es.

Estos casos son sólo una muestra de la imagen que se presenta de la mujer y las múltiples formas de violencia que sufre. 
Por todo lo explicado anteriormente, la hipótesis que afirma que los medios de comunicación social presentan en general una imagen negativa de la mujer en nuestra sociedad, se cumple ampliamente. En efecto, la imagen de la mujer que se presenta en la televisión a través de los programas y la publicidad, es la de una mujer en un rol conservador, pasivo, decorativo, fuertemente erotizado, y que no muestra la real situación de este grupo humano tan importante para la sociedad en la que contribuye y participa desde diferentes dimensiones políticas, económicas y sociales.

La otra hipótesis que afirma que la televisión privilegia la información de violencia contra la mujer desde un punto de vista sensacionalista, también queda confirmada. El sensacionalismo enfatiza el impacto inclusive superficial de los hechos sin detenerse en el análisis, interpretación y contextualización de la información.

Estas dos constataciones permiten afirmar que los medios no contribuyen a la solución efectiva del problema de la violencia contra la mujer, que como hemos afirmado, sigue creciendo de manera alarmante en nuestra sociedad. y ello es porque la televisión no informa de manera completa, integral y analítica el problema, no orienta adecuadamente, no hace un seguimiento judicial de los casos hasta las sentencias del agresor, no identifica a éste sino que muchas veces lo enmascara , y en general no realiza un tratamiento informativo correcto de hecho de la violencia.

\section{Conclusiones}

1. La violencia contra la mujer es un problema grave en el Perú con consecuencias negativas en el terreno social, político, económico, educativo y humano.

2. La violencia contra la mujer no es un fenómeno aislado, delincuencial, sino que evidencia las relaciones de poder en nuestra sociedad a favor del hombre donde al primero se le enseña que es el dominador y a la segunda la dominada. A pesar de los grandes esfuerzos por superar la inequidad social en este terreno, lo cierto es que a la mujer todavía se le niega oportunidades y responsabilidades que si tiene el varón.

3. La televisión refleja profundamente esta situación pero a la vez añade un tratamiento informativo que refuerza el rol devaluado de la mujer y que no presenta los hechos de violencia en su real dimensión.

4. El tratamiento informativo de la violencia contra la mujer tiende al sensacionalismo y no contribuye al análisis y contextualización del problema para orientar mejor al público y hacerlo tomar conciencia de la gravedad de la situación. 
5. Si bien es cierto que es el varón el agresor de la mujer también se observa que son otras mujeres las que agreden y no sólo pertenecen al ámbito familiar de la víctima sino que muchas veces son policías, juezas y expertas.

Urge entonces la capacitación de periodistas especialistas en este tipo de información que ofrezcan una información veraz, integra, con el análisis y la contextualización requeridas. Esta labor no se debe dejar en manos de los periodistas de policiales cuya formación muchas veces no es periodística y que lleva a distorsiones en sus rutinas profesionales que, como se ha analizado antes, no contribuyen a una información correcta.

\section{Referencias bibliográficas}

FERNÁNDEZ VILLANUEVA, Concepción y otros (2007). "Legitimación de la violencia en la televisión y en la vida social”. En Violencia en los medios de comunicación, Madrid, 21.

INSTITUTO NACIONAL DE ESTADÍSTICA E INFORMÁTICA (INEI) (2006). Violencia conyugal física en el Perú. Distribución regional, caracterización de víctimas y agresores, factores asociados y consecuencias de un problema de salud pública. Lima: Centro de investigación y desarrollo.

LÓPEZ DIEZ, Pilar (2002). "La violencia contra las mujeres en los medios de comunicación”. En Mujer, violencia y medios de comunicación. Dossier de prensa. Madrid: Instituto oficial de radio y televisión/Radio televisión española,

RODIGOU, MAITÉ y otros (2007). La violencia hacia las mujeres en los medios de comunicación. Transformando las noticias. Córdoba: Centro de intercambio y servicios para el Cono Sur Argentina.

VALLEJO RUBINSTEIN, Claudia (2002). Representación de la violencia contra las mujeres en la prensa española (El país/ El mundo) desde una perspectiva crítica de género. Un análisis crítico del discurso androcéntrico de los medios. Tesis de doctorado de comunicación social. Barcelona, Universidad Pompeu Fabra. 